Development and Validation of the Boardgaming Motivations Scale Joe A. Wasserman ${ }^{\mathrm{a}}$ and Julia K. Weiss ${ }^{\mathrm{b}}$

${ }^{\text {aRTI International }}$

bThe University of Virginia's College at Wise

Author Note

Joe A. Wasserman, Center for Advanced Methods Development, RTI International; Julia K. Weiss, Department of Communication Studies, The University of Virginia's College at Wise.

Correspondence concerning this paper should be addressed to Joe Wasserman. E-mail: joe.wasserman@gmail.com 
Abstract: Games, and boardgames specifically, are an increasingly central part of many individuals' media diets. Boardgames also have immense potential as naturalistic laboratories for studying psychological phenomena, providing players opportunities for small-group and interpersonal interactions with social, emotional, and cognitive consequences. Although different boardgaming motivations likely modulate these processes and outcomes, no grounded, validated instrument exists to measure them. This three-study investigation explored gaming motivations of and gratifications enjoyed by boardgamers (Study 1) and drew from this exploration to develop the Boardgaming Motivations Scale (Study $2 ; N=1,045$ ). Exploratory structural equation models provided initial evidence of the scale's validity (Study 2 ). The scale was further refined, confirmed, and validated with an independent sample of less involved boardgamers (Study 3; $N=652$ ). The diverse pool of motivations for playing boardgames inductively identified in Study 1 were reduced to seven dimensions in Study 2 and finally to six in Study 3. These dimensions reflected lusory, immersion, group sociality, community, escapism, and mastery boardgaming motivations. Relationships among these motivations and preferences for boardgame mechanics and genres, individual differences, and videogaming motivations provided initial evidence of the construct, convergent, predictive, and discriminant validity of the Boardgaming Motivations Scale. Supplemental material and data: https://osf.io/cqusx/ Keywords: board games, uses \& gratifications, measurement instrument development, exploratory structural equation models 


\section{Development and Validation of the Boardgaming Motivations Scale}

From Eurogames (with simple rules and indirect conflict) to Ameritrash (complicated, themed, and luck-based), boardgames are a diverse class of games with a diverse range of players - and have grown in popularity to a $\$ 495$ million market (Griepp, 2018). Boardgames are tangible, interactive media typically played face-to-face by multiple individuals who manipulate the game's physical components to execute actions and track game states. They provide a context for phenomena of interest to psychology and communication scholars, such as interpersonal communication (Woods, 2012), relationship formation or maintenance (Rogerson \& Gibbs, 2018), and small-group dynamics (Xu, Barba, Radu, Gandy, \& MacIntyre, 2011). Communication occurs not only between turns, but is central to how the game unfolds: collaboratively learning rules and mechanics - and negotiating, arbitrating, and enforcing rulesis necessary for play (Xu et al., 2011). Boardgames share characteristics with other media as mass-produced artifacts that, like television and books, may be found enjoyable and meaningful (cf. Oliver \& Raney, 2011), but also convey content with potential 'serious' outcomes, such as improved systems thinking (Kaufman \& Flanagan, 2016).

Within psychological sciences, research interest in boardgames dates back to at least the early 20th century (e.g., Cleveland, 1907). Since then, empirical research on games and gaming through both applied and entertainment media lenses has grown. From an applied or 'serious games' perspective, research has examined games on diverse topics including training detection of deception cues (Dunbar et al., 2018), promoting healthy diets (Peng, 2009), and encouraging physical activity (Ahn et al., 2015). (For recent general reviews, see Boyle et al., 2016; Granic, Lobel, \& Engels, 2014). As entertainment media, research has examined topics as diverse as game preferences and selection (Sherry, Lucas, Greenberg, \& Lachlan, 2006), enjoyment of 
exercise games (McGloin \& Embacher, 2018), and mood repair (Reinecke et al., 2012).

Calls for utilizing games as naturalistic, manipulable, and controllable laboratories have been made across social sciences from psychology (Freedman \& Flanagan, 2017) and cognitive science (Gray, 2017) to epidemiology (Lofgren \& Fefferman, 2007). Boardgames have been applied in this vein at least since the mid-20th century, such as using Parcheesi to study coalition formation (Vinacke \& Arkoff, 1957), but have since been overtaken by the growth of digital gaming. In comparison to videogames, boardgames have both strengths and weaknesses for use in scientific studies. Boardgames cannot be delivered digitally and typically require multiple participants simultaneously. However, unlike videogames, they provide naturalistic contexts for face-to-face communication and social interaction, do not disadvantage participants unfamiliar with videogame controls, and can be custom-built or modified with less time, money, and technical resources. Given these strengths, boardgames have immense untapped potential for application within the socio-psychological sciences, and there is a need for tools to support these endeavors.

Although myriad works have explored individuals' motivations for engaging digital games (e.g., Sherry et al., 2006) and how these motivations influence gameplay experiences and outcomes (Sherry, 2013), no extant literature has inductively derived and validated a typology and measurement instrument of boardgaming motivations for use in research on or utilizing boardgaming (cf. Yee, 2017). Thus, it is unclear whether existing research on videogaming motivations can be applied to boardgaming. The three studies reported in this paper bridge this gap by inductively examining boardgamers' subjective drive for playing boardgames (Study 1), drawing from that exploration to develop and validate the Boardgaming Motivations Scale (Study 2), and confirming the structure of and further validating this scale in an independent 
sample (Scale 3).

\section{Review of Literature}

Whether played for entertainment or serious ends, the consequences and derived experiences of gameplay depend on players' motivations for play (Sherry, 2013). In voluntary play contexts, individuals' choices of boardgames to play likely depend on their motivations for playing them in the first place (see Rosengren, 1974). Game selection, in turn, influences experiences and consequences of gameplay (Bowman \& Tamborini, 2015). To understand the experience and effects of playing boardgames, we must first understand the motivations that drive gamers to play.

The uses and gratifications paradigm (U\&G; Rosengren, 1974; Rubin, 1983) is concerned with the variably active role individuals take in their media consumption. Through this lens, media consumption such as playing boardgames is driven by biological, psychological, and social needs. Based on more or less conscious perception of these needs, individuals perceive both deficiencies in their current states and solutions for mitigating these deficiencies. Taken together, these perceptions generate motivations for behaviors principally including media consumption, which manifest as the selection and use of media or other functional alternatives that are perceived to provide the same benefits. Individuals anticipate and perceive outcomes of specific media use, toward feeling that deficiencies have been addressed (gratification) or not (non-gratification). Unlike other media-consumption perspectives that see media selection as a relatively unconscious series of satisficing decisions (e.g., selective exposure; Zillmann \& Bryant, 1985), U\&G emphasizes the active role of consumers in media selection.

Given that videogames and boardgames have interconnected lineages (Peterson, 2012) and share characteristics such as rules, variable outcomes, and player effort (Juul, 2011), 
motivations for playing the two may partially overlap. Despite spanning over 30 years, many types of videogames, and varied participant demographics, six videogaming gratifications stand out as consistent across studies (e.g., Barnett et al., 1997; Selnow, 1984; Sherry et al., 2006; Yee, 2006): diversion, sociality, arousal, challenge, competition, and fantasy. Broadly drawing from this body of research, diversion is the use of videogames to pass the time, reduce stress, relax, or escape from daily worries. Sociality is the use of videogames to interact with others, including general social interaction and shared social gaming experiences. Arousal is the use of videogames to experience feelings of excitement, alertness, and adrenaline, or the opposite of boredom. Challenge is the use of videogames to not only encounter difficult situations, but to experience competence and mastery by overcoming them. Competition is the use of videogames to pit one's abilities against others' and to out-perform them. Fantasy is the use of videogames to experience other worlds, be a different person, or immerse oneself in a different environment.

Despite similarities between boardgames and videogames, boardgames' differences may yield distinct motivations for play. While objects in videogames are digital, those in boardgames are tangible (Ip \& Cooperstock, 2011), which may yield motivations related to tangibility. Most boardgames are turn-based, while most videogames are real-time, perhaps yielding less motivation related to arousal and more related to cognitive contemplation. Because boardgames are typically played with small face-to-face groups (Xu et al., 2011), while videogames are typically played alone or online multiplayer (see Jansz \& Tanis, 2007), boardgaming may be associated with motivations for face-to-face contact. Because boardgames require players to enforce rules, unlike videogames that use software to enforce rules (Xu et al., 2011), players must have explicit understanding of those rules, which may generate motivations related to understanding or implementing boardgame rules systems. Videogames are more easily able to 
display additional information to players than boardgames (Rogerson, Gibbs, \& Smith, 2015), so boardgame play may be motivated by the challenge of intuiting key information during play. Boardgamers also represent a distinct community with their own norms (Woods, 2012), from which community-oriented motivations may arise. Given these differences between boardgames and videogames, it may be expected that the gratifications of each overlap but are not identical.

Research on boardgaming motivations has focused on boardgaming as a hobby broadly (Rogerson, Gibbs, \& Smith, 2016) or on enjoyment of boardgames rather than motivations (Woods, 2012), or is only commercially available and based on untested assumptions that boardgaming motivations are similar to videogaming motivations (Yee, 2016). As such, there is a need for an empirically-grounded, valid instrument for measuring motivations for playing boardgames. In past research on the enjoyment of boardgaming, hobbyists most frequently mentioned the following pleasures of gameplay in descending order: social interaction, strategic play, intellectual challenge, in-game interaction, competition, integrated theme, tactical play, shared fun, attractive components, interesting mechanics, tactility, narrative, learning new games, winning, immersion, and mastery (Woods, 2012). More recently, semi-structured interviews with boardgame hobbyists (Rogerson et al., 2016) have identified four domains of boardgame enjoyment broadly: sociality, intellectual challenge, game variety, and materiality.

While aforementioned research on boardgaming enjoyment and motivations have yielded novel insights, their particular strengths are accompanied by weaknesses limiting their utility for large-scale academic research on boardgaming: either they are large-scale but deductively based on digital gaming research (Yee, 2016), inductive but based on limited samples and emphasize the hobby broadly as opposed to play specifically (Rogerson et al., 2016), or focus on enjoyment as a narrow aspect of potentially more diverse motivations for boardgaming (Woods, 2012). We 
leveraged these approaches' strengths by taking a grounded approach to inductively identify gratifications of playing boardgames (Study 1), followed by a large-scale, quantitative approach to develop and validate the Boardgaming Motivations Scale (Study 2), concluding with a second quantitative study that confirmed and further validated this measurement instrument (Study 3).

\section{Study 1: Identifying Boardgaming Motivations and Gratifications}

\section{Method}

Following approval from the university’s Institutional Review Board, participants were recruited from boardgaming-related online discussion forums to specifically garner participation from individuals who are known to play boardgames more diverse than mainstream classics such as Monopoly or Candy Land, thus mitigating the need to provide participants a definition of "boardgames" that would likely have caused contention among participants. After reviewing consent information, participants completed an online questionnaire. After completing the questionnaire, participants were able to opt into a drawing for one $\$ 50$ gift card.

\section{Participants}

Participants $(N=374)$ were, on average, 38.46 years old $(S D=10.55)$. Most reported sex as male $(n=312,85.01 \%)$, followed by female $(n=49,13.35 \%)$ and nonbinary $(n=2,0.54 \%)$. Most reported race as White $(n=310,85.40 \%)$, followed by Asian $(n=20,5.51 \%)$, multiple races $(n=17,4.68 \%)$, and others $(n=16,4.41 \%)$. Most reported holding at least a four-year degree $(n=289,78.12 \%)$ and had played boardgames on average for 12.12 years $(S D=12.75)$.

\section{Measures}

Five open-ended questions were designed to elicit detail about participants' motivations 
(reasons for playing) and gratifications (anticipated satisfactions or rewards from playing) ${ }^{1}$ associated with playing boardgames. Participants were first asked, "What are your reasons for playing board games?" followed by three comparison-based probes: "When you choose to play board games instead of engaging in other activities or media consumption, what are your reasons for doing so?," "Why do you choose to play certain board games over others?," and "Have your reasons for playing board games changed over time? If so, how?" Finally, to elicit any potential gratifications that participants may not already have described, they were asked, "Are there any benefits that you think you get from playing board games in addition to those that you may have already described in earlier questions? If so, what are they?"

\section{Data Analysis}

The first author (A1) and an assistant used inductive thematic analysis (Braun \& Clarke, 2006) to inductively derive motivations for playing boardgames from participants' open-ended responses. This analysis was performed in the following steps by A1: (1) deep familiarization with data through careful reading; (2) granular coding of reasons for playing boardgames generally or in contrast to other activities ${ }^{2}$, yielding 827 non-unique codes; and (3) sorting initial codes into 28 clusters of similar motivations. Open coding (step 2) was conducted until saturation (Bowen, 2008), or the point at which no additional motivations were being identified in the data (achieved at $n=135$ ). For a liberal threshold for identifying new motivations, saturation was operationalized as analyzing the responses of 15 participants in a row without identifying any novel motivations. Following, (4) both authors checked clusters for consistency

\footnotetext{
${ }^{1}$ For brevity, motivations and anticipated gratifications will be referred to as "motivations."

${ }^{2}$ Anything that could be interpreted as a motivation (a reason or drive for playing) or gratification (a potential satisfaction, reward, or benefit from playing) was coded.
} 
and split them when they reflected more than one motivation, resulting in 56 categories; (5) A1 reviewed clusters of motivations for between-cluster differentiability and re-grouped duplicative categories, for a final 48 motivations. Then, (6) A1, A2, and an assistant independently grouped similar clusters into higher-level categories, (7) A1 identified similarities among these groupings to generate the final high-level categories of motivations that were (8) inspected and approved by A1, A2, and an assistant.

\section{Results}

This emergent thematic analysis yielded three high-level categories of motivations: intellectual, entertainment, and social (Table 1). Intellectual motivations are related to thinking (e.g., need for cognition; see Cacioppo \& Petty, 1982), learning (e.g., learning via simulation), and cognitive effort or challenge (e.g., complexity). Entertainment motivations are related to mood management (e.g., fun and relaxation; see Zillmann \& Bryant, 1985), emotional experiences (e.g., emotional flow), and media qualities (e.g., narratives, non-digital). Social motivations are those related to interactions and relationships with other people (e.g., community, new relationships), reflecting needs for relatedness (Deci \& Ryan, 2000). (See supplemental Table S1 for exemplars of all motivations).

\section{Brief Discussion}

The three high-level intellectual, entertainment, and social motivation themes parallel Olson's (2010) synthesis of videogame play motivations as intellectual, emotional, and social. Aforementioned primary videogame gratifications of diversion, sociality, challenge, competition, and fantasy were present. Arousal was conspicuously absent, possibly due to boardgames' typically sedate, turn-based nature. All boardgaming motivations previously identified (Rogerson et al., 2016; Woods, 2012) were present except integrated theme and attractiveness, although 
adjacent gratifications (immersion/fantasy, tangibility) were identified.

Table 1

Inductively Derived Motivations for Playing Boardgames

\begin{tabular}{|c|c|c|c|}
\hline $\begin{array}{l}\text { Motivation } \\
\text { Theme }\end{array}$ & & $\begin{array}{c}\text { Motivation } \\
\text { Code Categories }\end{array}$ & \\
\hline \multirow[t]{7}{*}{ Intellectual } & $\begin{array}{l}\text { Adapting to changing } \\
\text { circumstances }\end{array}$ & Cognitive growth & $\begin{array}{l}\text { Common ground for } \\
\text { competition }\end{array}$ \\
\hline & Competition & Complexity & Didactic \\
\hline & Game mechanics & Game skill development & In-game interaction \\
\hline & Interactivity & Interest in topic or theme & Learning via simulation \\
\hline & Long-term strategy & $\begin{array}{l}\text { Meaningful decisions versus } \\
\text { randomness }\end{array}$ & Need for cognition \\
\hline & Newness versus familiarity & Personal challenge & Player-driven challenge \\
\hline & Rules expertise & Understanding others & Intellectual validation \\
\hline \multirow{4}{*}{$\begin{array}{l}\text { Entertainmen } \\
\mathrm{t}\end{array}$} & Acceptable adult play & Building and creating & Consequence-free \\
\hline & Emotional flow & Enjoying the journey & Escapism \\
\hline & Fun and relaxation & Immersion and fantasy & Narratives \\
\hline & Non-digital & Physical accessibility & Tangibility \\
\hline \multirow[t]{5}{*}{ Social } & $\begin{array}{l}\text { Common ground for social } \\
\text { interaction }\end{array}$ & Community & Existing relationships \\
\hline & Face-to-face & Group engagement & Hobby evangelization \\
\hline & Interpersonal skills & Like-minded others & New relationships \\
\hline & Para-gameplay interaction & Shallow relationships & Social alternative \\
\hline & Social gameplay dynamics & Social scaffolding & Solo play \\
\hline
\end{tabular}

Several identified motivations appear to be novel, such as social scaffolding to overcome interaction difficulties, as an alternative to other social activities such as going to a bar or watching sports, and seeking non-digital and face-to-face gameplay. Because boardgaming motivations appear distinct from videogaming motivations, Study 2 was undertaken to develop a self-report measure of motivations for playing boardgames specifically.

\section{Study 2: Boardgaming Motivations Scale Development and Validation}

\section{Method}

Following approval from the university's Institutional Review Board, parallel to Study 1, participants were recruited from boardgaming-related online discussion forums and social media groups to participate in an online survey about motivations for playing boardgames. The online questionnaire contained closed-ended questions about motivations for playing boardgames, 
boardgame preferences, and identification with gamer groups, as well as demographic variables. After completing the questionnaire, participants were able to opt into a drawing for one $\$ 50$ gift card.

\section{Participants}

Participants $(N=1,045)$ were on average 36.52 years old $(S D=10.06)$. Most reported gender as male $(n=802,78.17 \%)$, followed by female $(n=218,21.25 \%)$ and nonbinary $(n=6$, $0.58 \%)$. Most reported race as White $(n=908,89.63 \%)$, followed by Asian $(n=51,5.03 \%)$. Most reported holding at least a four-year degree $(n=897,86.08 \%)$, living in the United States $(n=595,57.8 \%)$, and having played boardgames for an average 11.64 years $(S D=11.18)$.

\section{Measures}

Boardgaming motivations. Based on Study 1 results, items were developed to measure each of the 48 granular gratifications; these comprised the initial Boardgaming Motivations Scale (BGMS) item pool. During this process, gratifications that appeared to contain dichotomies were split (e.g., meaningful decisions versus randomness were split into two categories), yielding a final total of 55 gratifications with two items apiece, totaling 110 items representing motivations for play (see supplemental Table S2 for the complete item list). To ensure comprehensibility, items were reviewed by a hobby boardgamer and two non-boardgamers (including A2) and iteratively revised for precision, clarity, and face validity. In the survey, items were presented in random order, and participants were asked to rate their agreement (from $1=$ strongly disagree to $7=$ strongly agree). Covariance coverage exceeded $98.9 \%$ for all pairs of items.

\section{Validation Measures}

Different motivations for playing boardgames should yield preferences for different types of boardgames that have variable ability to obtain particular gratifications, as has been found for 
videogames (e.g., Sherry et al., 2006). Additionally, U\&G posits that individual differences and societal factors combine to shape perceived needs, and thereby motivations for behaviors to gratify those needs (Rosengren, 1974). Thus, individual differences such as demographics and identity should influence motivations for playing boardgames. Several validation measures were included to investigate these possibilities.

Boardgame preferences. Boardgame preferences were measured through affective evaluations of (a) the 51 boardgame mechanics listed in the BoardGameGeek database (e.g., "worker placement" and "trading") and (b) the eight boardgame genres in the BoardGameGeek database (e.g., "abstract games" and "strategy games"), plus three commonly-used categories. See supplemental Table S3 for descriptives of genre preferences. All mechanics and genres were presented in random order on separate pages as Likert-style items $(1=$ dislike a great deal to $7=$ like a great deal). After reducing dimensionality via exploratory factor analysis (EFA), boardgame mechanics reflected five dimensions: economic $(M=4.58, S D=1.07)$, wargame $(M$ $=4.91, S D=0.75)$, cardgame $(M=5.76, S D=1.11)$, acting $(M=4.36, S D=1.48)$, and patternmatching $(M=5.03, S D=1.12)$ (see supplemental material section 2.1 for EFA details). It was expected that boardgaming motivations would be more positively associated with preferences for boardgame genres and mechanics that are able to provide their sought-after gratifications.

Identification with gamer groups. Participants' identification with seven groups of gamers, including boardgamers and Eurogamers (Woods, 2012), were each evaluated with single, five-option pictorial items (from 1 to 5) measuring identity fusion (Swann Jr., Gómez, Conor, Francisco, \& Huici, 2009), which were adapted from earlier pictorial measures of group identification (Schubert \& Otten, 2002). Prior to analyses, identification with grognards (a term for old-school wargamers) was dropped for strongly correlating with identification with 
wargamers $(r=.65, p<.001)$. See supplemental Table S4 for descriptives. Those whose identities were connected to various groups of gamers were expected to have different motivations for playing boardgames.

Demographics. Participants were asked to report their age, education level, gender, race/ethnicity, and current country of residence. Except for education level, which included eight options, all questions were open-ended and coded by the first author.

\section{Data Screening}

Prior to analysis, to eliminate low-quality responses, responses on questionnaire pages on which participants spent less than one second per item were replaced with missing values (see Wood, Harms, Lowman, \& DeSimone, 2017). For most pages of measures, only one-to-four participants' responses were nulled for speeding. For identification with gamers, 23 participants' responses were nulled.

\section{Boardgaming Motivations Scale Exploratory Factor Analysis}

To identify the underlying factor structure of the initial 110 BGMS pool items and to reduce the number of items to a reasonable quantity, all items were subjected to exploratory factor analysis using maximum likelihood (ML) estimation with oblique geomin rotation. Because little was known a priori about this factor structure, this rotation was selected both to allow factors to correlate and to more accurately identify cross-loadings than other oblique rotations (Asparouhov \& Muthén, 2009). To arrive at a factor solution with high discriminant validity, items were iteratively dropped starting with items without any standardized factor loadings $>.32$ and finally dropping items without standardized loadings $>.6$ on any one factor or with standardized loadings $\geq .2$ on any other factor. The number of factors retained at each step was determined using parallel analysis, comparing observed Eigenvalues to the 95th percentile 
of Eigenvalues generated from random data (Hayton, Allen, \& Scarpello, 2004). In the final step, one item with a primary loading just below .6 was retained and a two-item factor that appeared to reflect an affinity for simple games, rather than a true motivation, was dropped. After ten iterations, a seven-factor, 28-item model was retained (Table 2$), \chi^{2}(329, n=1044)=1028.109, p$ $<.0001, \mathrm{RMSEA}=.045$ (90\% CI: .042, .048), CFI $=.942, \mathrm{SRMR}=.044$. There were no large and significant correlation residuals ${ }^{3}$. Factor intercorrelations were modest (Table 3), supporting the discriminant validity of BGMS's dimensions. Model comparisons indicated that fixing crossloadings to zero (i.e., a typical independent clusters model CFA) resulted in substantially worse model fit, $\chi^{2}(203, n=1044)=480.692, p<.0001$, RMSEA $=.036(90 \% \mathrm{CI}: .032, .040)$, CFI $=$ $.977, \operatorname{SRMR}=.015, \Delta \chi^{2}(\Delta d f=126)=547.417, p<.001$. Therefore, subsequent validation analyses were performed using exploratory structural equation models (ESEM) in which all BGMS items were allowed to load on all factors (Marsh, Morin, Parker, \& Kaur, 2014).

The dimensions of boardgaming motivations retained in the BGMS drew from all three high-level categories of gratifications identified in Study 1: intellectual (lusory, player interaction, mastery), entertainment (immersion, escapism), and social (group sociality, community). Notably, no BGMS dimensions combined items from multiple high-level gratification categories, thus supporting the face validity of the initial classification and the BGMS.

${ }^{3}$ To mitigate against capitalizing on chance and overfitting to sample-specific variance, only correlation residuals that were moderately large (i.e., correlation residuals $>.10$ ) and significant (i.e., standardized correlation residual of $\geq 1.96$ ) were investigated as potential indicators of local misfit. 
Table 2

Boardgaming Motivations Scale Exploratory Factor Analysis Results

\begin{tabular}{|c|c|c|}
\hline Factor & Item text & $\begin{array}{c}\text { Primary } \\
\text { Std. } \\
\text { Loading }\end{array}$ \\
\hline 1. Lusory & When I play boardgames, I don't care if I win. & 0.887 \\
\hline$M=5.16$ & Winning isn't important when I play boardgames. & 0.865 \\
\hline $\begin{array}{l}S D=1.33 \\
\alpha=\quad .84\end{array}$ & I boardgame for the activity of playing, not the outcome. & 0.637 \\
\hline 2. Immersion & I play boardgames for an interactive storytelling experience. & 0.837 \\
\hline$M=4.67$ & I play boardgames for the stories that emerge through gameplay. & 0.832 \\
\hline$S D=1.37$ & I play boardgames to get immersed in their worlds. & 0.788 \\
\hline$\alpha=.87$ & Boardgames let me lose myself in a different world. & 0.645 \\
\hline 3. Group & I play boardgames because they involve gathering around a table with others. & 0.812 \\
\hline sociality & I play boardgames because they engage a whole group. & 0.742 \\
\hline$M=5.57$ & I play boardgames to socialize with others around the game. & 0.709 \\
\hline$S D=1.01$ & I play boardgames to be face-to-face with others. & 0.681 \\
\hline$\alpha=\quad .87$ & $\begin{array}{l}\text { Boardgaming provides shared group experiences. } \\
\text { I play boardgames because they are a common focus for social interaction. }\end{array}$ & $\begin{array}{l}0.655 \\
0.626\end{array}$ \\
\hline 4. Community & I play boardgames to make friends I never would have met otherwise. & 0.889 \\
\hline$M=4.30$ & Boardgaming provides me new ways to make new friends. & 0.826 \\
\hline$S D=1.37$ & I play boardgames to meet like-minded people. & 0.701 \\
\hline$\alpha=\quad .86$ & I play to engage with the boardgame community. & 0.636 \\
\hline 5. Mastery & I play boardgames for the personal challenge of figuring out a game. & 0.758 \\
\hline$M=5.52$ & I boardgame for the opportunity to figure out how to master a game. & 0.678 \\
\hline$S D=0.91$ & I play boardgames to solve challenging puzzles. & 0.601 \\
\hline$\alpha=\quad .75$ & It's gratifying to think of ways to play a boardgame more effectively. & 0.595 \\
\hline 6. Escapism & I play boardgames to relieve stress. & 0.712 \\
\hline$M=5.44$ & Boardgames let me escape everyday pressures. & 0.692 \\
\hline$S D=0.97$ & Playing boardgames provides a break from daily life. & 0.655 \\
\hline$\alpha=\quad .76$ & Playing boardgames helps me relax. & 0.607 \\
\hline 7. Player & Boardgames are most gratifying when players' moves influence each other. & 0.848 \\
\hline interaction & I'm drawn to boardgames that make me react to others' decisions. & 0.646 \\
\hline$M=5.28$ & Boardgames are most satisfying when others' moves don't influence how I play. (r) & 0.642 \\
\hline $\begin{array}{l}S D=1.02 \\
\alpha=.74\end{array}$ & & \\
\hline
\end{tabular}

Note. Factor loadings are primary standardized loadings, all $p<.001$. Descriptives are based on composites of observed variables. See supplemental Table S5 for complete standardized pattern coefficients.

Lusory motivations are those for which play is an end in itself, and any instrumental outcomes related winning are unimportant (Suits, 2014). Immersion motivations are related to becoming psychologically engrossed in a game world (Lombard \& Ditton, 1997), accepting the rules that govern the functioning of the game world (Arsenault, 2005), and the emergent narratives that arise during play (Jenkins, 2004). Group sociality motivations involve multiple individuals interacting with each other while simultaneously engaged with the same gameplay 
activity, supporting the notion that boardgaming focuses players on shared physical spaces

(Nicholson \& Begy, 2014). Community motivations are about forming social relationships with others who share one's values and interests (cf. Steinkuehler \& Williams, 2006). Mastery motivations are the desire to gain a deep understanding of a game in order to play at a high level, reflecting needs for competence (Deci \& Ryan, 2000). Escapism motivations involve playing boardgames for stress reduction, relaxation, and as a break from everyday stressors (Zillmann \& Bryant, 1985). Player interaction motivations focus on a particular kind of sought-after gameplay experience, one in which players' decisions are interdependent.

Table 3 Partial Correlations among Boardgaming Motivations Scale Dimensions

\begin{tabular}{lcccccc}
\hline & \multicolumn{7}{c}{ Factor } \\
\cline { 2 - 7 } Factor & 1 & 2 & 3 & 4 & 5 & 6 \\
\hline 1. Lusory & - & & & & & \\
2. Immersion & $\mathbf{. 1 7 6}$ & - & & & & \\
& $(<.001)$ & & & & & \\
3. Group sociality & $\mathbf{. 1 9 9}$ & $\mathbf{. 1 8 8}$ & - & & & \\
& $(<.001)$ & $(<.001)$ & & & & \\
4. Community & $\mathbf{. 0 7 0}$ & $\mathbf{. 1 5 1}$ & $\mathbf{. 4 1 3}$ & - & & \\
& $(.039)$ & $(<.001)$ & $(<.001)$ & & & \\
5. Mastery & $\mathbf{- . 1 7 9}$ & -.001 & -.021 & .068 & - & \\
& $(<.001)$ & $(.971)$ & $(.543)$ & $(.051)$ & & \\
6. Escapism & $\mathbf{. 1 5 9}$ & $\mathbf{. 2 8 6}$ & $\mathbf{. 2 6 1}$ & $\mathbf{. 2 2 9}$ & $\mathbf{. 0 9 0}$ & - \\
& $(<.001)$ & $(<.001)$ & $(<.001)$ & $(<.001)$ & $(.014)$ & \\
7. Player interaction & -.045 & $\mathbf{. 0 7 2}$ & $\mathbf{. 3 3 3}$ & .067 & $\mathbf{. 1 4 0}$ & -.013 \\
& $(.207)$ & $(.038)$ & $(<.001)$ & $(.050)$ & $(<.001)$ & $(.720)$ \\
\hline
\end{tabular}

Note. $p$-values are in parentheses. Bolded correlations are $p<.05$.

\section{Boardgaming Motivations Scale Validation Analyses}

To assess the degree to which BGMS dimensions predicted preferences for boardgame mechanics, all boardgame mechanic factors were regressed on all BGMS dimensions using maximum likelihood estimation with robust standard errors (MLR) to adjust standard errors of parameter estimates for any potential non-normality in the data (Table 4). Although the structural model was just-identified (i.e., paths or covariances were included among all exogenous and endogenous variables), and although the test of exact fit was failed, other fit indices suggested 
close global fit, $\chi^{2}(745, n=1045)=1501.520, p<.0001, \mathrm{RMSEA}=.031(90 \% \mathrm{CI}: .029, .033)$, $\mathrm{CFI}=.954, \mathrm{SRMR}=.026$. This model had only five large and significant correlation residuals, all of which barely exceeded .10. Each dimension of boardgame mechanic preferences was predicted by a distinct combination of boardgaming motivations, supporting BGMS's overall predictive validity and the discriminant validity of individual dimensions. Although most BGMS dimensions were responsible for uniquely explaining a modest amount of preference for boardgame mechanics, immersion was a notable exception, strongly uniquely predicting preferences for acting boardgame mechanics, $\beta=.740, p<.001$.

Table 4

Boardgame Mechanic Preferences Regressed on BGMS

\begin{tabular}{|c|c|c|c|c|c|c|c|c|}
\hline & Lusory & Immersion & $\begin{array}{c}\text { Group } \\
\text { sociality }\end{array}$ & Community & Escapism & $\begin{array}{c}\text { Player } \\
\text { interaction }\end{array}$ & Mastery & $R^{2}$ \\
\hline & \multicolumn{8}{|c|}{ Economic Boardgame Mechanics } \\
\hline$\beta$ & -.038 & -.121 & .161 & .066 & .065 & .013 & .251 & .143 \\
\hline$S E$ & .039 & .041 & .049 & .042 & .043 & .046 & .045 & .027 \\
\hline$p$ & .336 & .003 & .001 & .121 & .132 & .786 & $<.001$ & $<.001$ \\
\hline$\beta$ & .025 & .213 & -.126 & .029 & .124 & .058 & .183 & .107 \\
\hline$S E$ & .042 & .043 & .060 & .048 & .048 & .051 & .049 & .024 \\
\hline \multirow[t]{2}{*}{$p$} & .552 & $<.001$ & .037 & .548 & .010 & .254 & $<.001$ & $<.001$ \\
\hline & \multicolumn{8}{|c|}{ Cardgame Mechanics } \\
\hline$\beta$ & .046 & .081 & .119 & .038 & .284 & .046 & -.062 & .117 \\
\hline$S E$ & .044 & .049 & .070 & .049 & .052 & .055 & .052 & .032 \\
\hline$p$ & .287 & .095 & .090 & .444 & $<.001$ & .406 & .235 & $<.001$ \\
\hline \multicolumn{9}{|c|}{ Acting Boardgame Mechanics } \\
\hline$\beta$ & -.005 & .740 & .207 & .020 & -.100 & -.057 & -.015 & .634 \\
\hline$S E$ & .031 & .028 & .053 & .034 & .036 & .034 & .037 & .034 \\
\hline$p$ & .869 & $<.001$ & $<.001$ & .552 & .005 & .089 & .678 & $<.001$ \\
\hline \multicolumn{9}{|c|}{ Pattern Boardgame Mechanics } \\
\hline$\beta$ & .023 & -.136 & .169 & .053 & .274 & .109 & -.178 & .144 \\
\hline$S E$ & .043 & .044 & .058 & .048 & .048 & .054 & .051 & .034 \\
\hline$p$ & .586 & .002 & .004 & .267 & $<.001$ & .043 & $<.001$ & $<.001$ \\
\hline
\end{tabular}

Note. Bolded standardized regression coefficients indicate $p<.05$.

To assess the degree to which BGMS dimensions predicted preferences for boardgame genres, all boardgame genre preference items were regressed on all BGMS dimensions using MLR estimation (Table 5). Although the structural model was just-identified, the measurement model had acceptable global fit, $\chi^{2}(434, n=1045)=770.357, p<.0001$, RMSEA $=.027(90 \%$ 
CI: .024, .030), CFI $=.974, \mathrm{SRMR}=.018$. This model had only one large and significant correlation residual. Each genre was predicted by a distinct configuration of boardgaming motivations, supporting BGMS's overall predictive validity and discriminant validity of individual dimensions. For most genres, BGMS explained a modest amount of variance in preferences $\left(R^{2}<.2\right)$, with three exceptions: party game preferences $\left(R^{2}=.202\right)$ were statistically significantly predicted primarily by group sociality motivations $(\beta=.771, p<.001)$, thematic game preferences $\left(R^{2}=.260\right)$ were statistically significantly predicted primarily by immersion motivations $(\beta=.768, p<.001)$, and solo game preferences $\left(R^{2}=.223\right)$ were statistically significantly predicted primarily by a combination of immersion motivations $(\beta=.515, p<.001)$ and group sociality motivations $(\beta=-.603, p<.001)$.

Table 5

Boardgame Genre Preferences Regressed on BGMS

\begin{tabular}{|c|c|c|c|c|c|c|c|c|}
\hline & Lusory & Immersion & $\begin{array}{c}\text { Group } \\
\text { sociality }\end{array}$ & Community & Escapism & $\begin{array}{c}\text { Player } \\
\text { interaction }\end{array}$ & Mastery & $R^{2}$ \\
\hline & \multicolumn{8}{|c|}{$\underline{\text { Abstract Games }}$} \\
\hline$\beta$ & .099 & -.202 & .128 & .051 & .141 & -.076 & .335 & .087 \\
\hline$S E$ & .053 & .058 & .068 & .058 & .066 & .058 & .059 & .023 \\
\hline$p$ & .064 & $<.001$ & .059 & .378 & .033 & .189 & $<.001$ & $<.001$ \\
\hline & \multicolumn{8}{|c|}{ Customizable Games } \\
\hline$\beta$ & -.053 & .595 & -.069 & .033 & .001 & .114 & .052 & .117 \\
\hline$S E$ & .061 & .065 & .086 & .068 & .080 & .079 & .071 & .022 \\
\hline$p$ & .384 & $<.001$ & .422 & .632 & .993 & .149 & .466 & $<.001$ \\
\hline \multicolumn{9}{|c|}{ Children's Games } \\
\hline$\beta$ & .118 & .037 & .128 & .130 & .157 & -.137 & -.134 & .068 \\
\hline$S E$ & .055 & .058 & .070 & .060 & .066 & .064 & .058 & .018 \\
\hline$p$ & .034 & .518 & .069 & .032 & .018 & .032 & .022 & $<.001$ \\
\hline & \multicolumn{8}{|c|}{$\underline{\text { Family Games }}$} \\
\hline$\beta$ & .028 & -.116 & .347 & -.038 & .118 & -.146 & .012 & .091 \\
\hline$S E$ & .046 & .048 & .066 & .044 & .053 & .054 & .047 & .023 \\
\hline$p$ & .543 & .015 & $<.001$ & .388 & .026 & .007 & .798 & $<.001$ \\
\hline & \multicolumn{8}{|c|}{$\underline{\text { Party Games }}$} \\
\hline$\beta$ & -.105 & .116 & .771 & -.051 & -.146 & -.118 & -.124 & .202 \\
\hline$S E$ & .059 & .063 & .077 & .059 & .069 & .057 & .056 & .030 \\
\hline$p$ & .076 & .066 & $<.001$ & .388 & .035 & .038 & .028 & $<.001$ \\
\hline & \multicolumn{8}{|c|}{ Strategy Games } \\
\hline$\beta$ & .000 & -.067 & -.030 & .041 & .006 & .083 & .318 & .120 \\
\hline$S E$ & .033 & .033 & .049 & .038 & .041 & .039 & .042 & .023 \\
\hline$p$ & .994 & .042 & .538 & .286 & .884 & .032 & $<.001$ & $<.001$ \\
\hline
\end{tabular}




\begin{tabular}{|c|c|c|c|c|c|c|c|c|}
\hline & Lusory & Immersion & $\begin{array}{l}\text { Group } \\
\text { sociality }\end{array}$ & Community & Escapism & $\begin{array}{c}\text { Player } \\
\text { interaction }\end{array}$ & Mastery & $R^{2}$ \\
\hline & \multicolumn{8}{|c|}{ Thematic Games } \\
\hline$\beta$ & -.055 & .768 & -.041 & -.053 & .038 & .129 & -.079 & .260 \\
\hline$S E$ & .048 & .053 & .069 & .056 & .063 & .067 & .055 & .028 \\
\hline$p$ & .252 & \multicolumn{6}{|c|}{ Wargames } & $<.001$ \\
\hline$\beta$ & -.122 & .363 & -.400 & .038 & .045 & .473 & -.082 & .118 \\
\hline$S E$ & .061 & .064 & .087 & .064 & .075 & .073 & .068 & .023 \\
\hline$p$ & .047 & \multicolumn{6}{|c|}{ Solo Games } & $<.001$ \\
\hline$\beta$ & .143 & .515 & -.603 & .161 & .223 & -.172 & .233 & .223 \\
\hline$S E$ & .059 & .060 & .076 & .069 & .071 & .073 & .066 & .027 \\
\hline$p$ & .016 & \multicolumn{6}{|c|}{ Eurogames } & $<.001$ \\
\hline$\beta$ & .038 & -.350 & .090 & .084 & .124 & -.133 & .389 & .191 \\
\hline$S E$ & .041 & .044 & .061 & .043 & .052 & .045 & .052 & .030 \\
\hline$p$ & .362 & $<.001$ & .142 & .053 & .018 & .003 & $<.001$ & $<.001$ \\
\hline & \multicolumn{8}{|c|}{ Cooperative Games } \\
\hline$\beta$ & .059 & .525 & .222 & -.070 & -.028 & -.330 & .187 & .184 \\
\hline$S E$ & .053 & .061 & .072 & .056 & .070 & .065 & .064 & .028 \\
\hline$p$ & .264 & $<.001$ & .002 & .207 & .689 & $<.001$ & .004 & $<.001$ \\
\hline
\end{tabular}

Note. Bolded standardized regression coefficients indicate $p<.05$.

To investigate the degree to which BGMS dimensions were related to individual differences, all BGMS dimensions were regressed on gender, age, and identification with six groups of gamers (Table 6). Of these exogenous variables, identification with gamer groups were allowed to covary. The initial model had seven large and significant correlation residuals, of which six involved age and gender. Because research has identified relationships between gamer identity and both age and gender (e.g., Vermeulen, Van Bauwel, \& Van Looy, 2017), residuals of videogamer and wargamer identification were allowed to covary with those of age and gender. Doing so eliminated all but two large and significant correlation residuals, both of which were just over .1. Despite failing the test of exact fit, other global fit indices suggested the revised model had acceptable global fit, $\chi^{2}(380, n=1013)=771.157, p<.0001$, RMSEA $=.031(90 \%$ CI: .028, .035), CFI $=.964, \mathrm{SRMR}=.021$. On average, after controlling for all other predictors, women reported over a third of a standard deviation greater community $(\beta=.352, p<.001)$ and over a quarter of a standard deviation greater escapism $(\beta=.261, p=.004)$, but more than a half 
standard deviation lower player interaction $(\beta=-.513, p<.001)$ motivations than men. Older participants reported lower group sociality $(\beta=-.023, p<.001)$ and player interaction motivations $(\beta=-.015, p<.001)$, both decreasing by about .02 standard deviations per additional year of age. Each boardgaming motivation was associated with a distinct pattern of identification with groups of gamers.

Table 6 BGMS Dimensions Regressed on Identification with Gamer Groups and Demographics

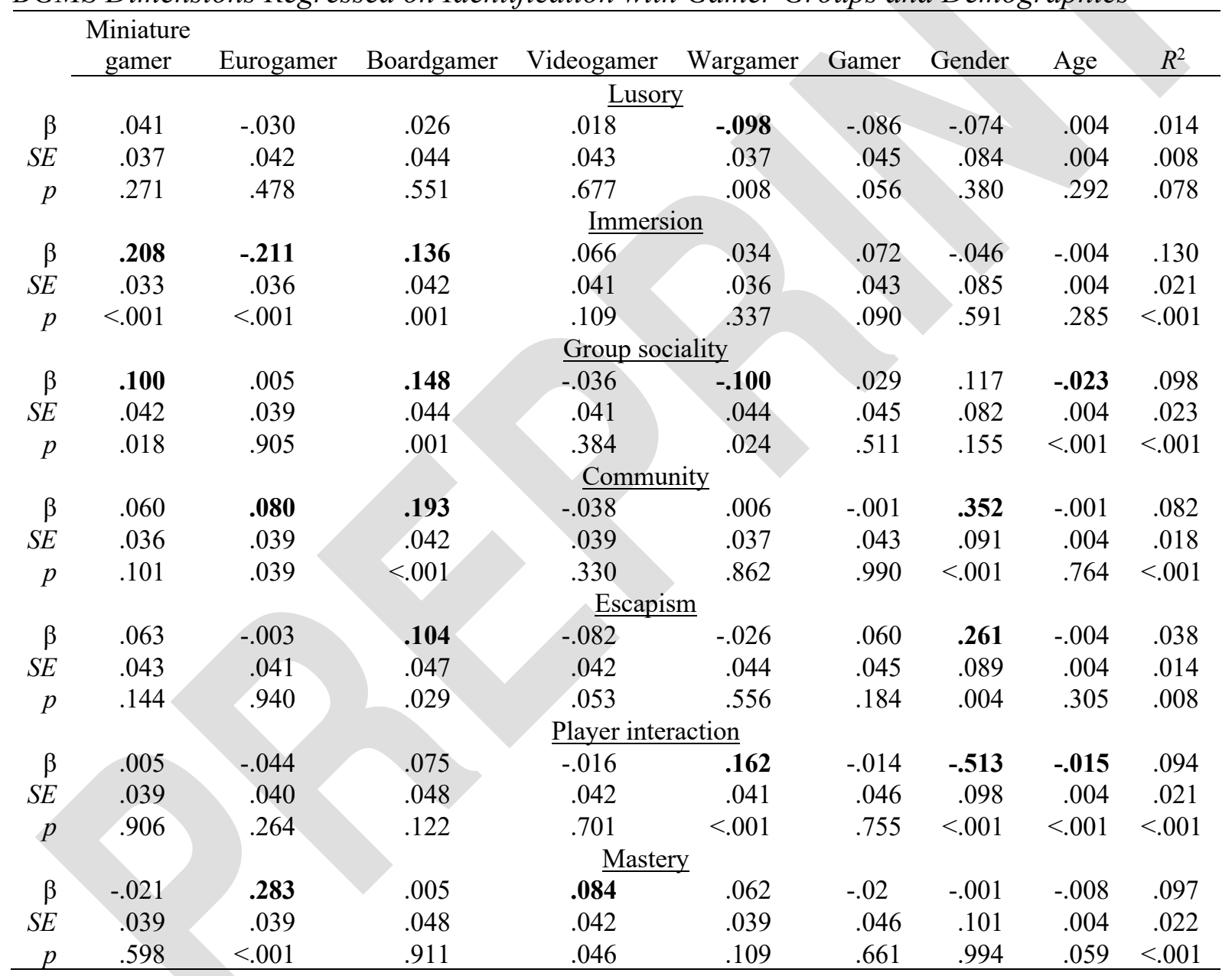

Note. Regression coefficients for BGMS on gamer group identification are completely standardized; regression coefficients for BGMS on gender (dummy-coded: $0=$ man, $1=$ woman) and age are partially standardized (unstandardized $\mathrm{X}$, standardized $\mathrm{Y}$ ). Bolded regression coefficients indicate $p<.05$.

\section{Brief Discussion}

A seven-factor, 28-item model of boardgaming motivations was obtained via EFA, 
reflecting lusory, immersion, group sociality, community, escapism, player interaction, and mastery motivations for playing boardgames. These BGMS dimensions exhibited distinct predictive patterns for participants' preferences for boardgame mechanics and genres. Individual differences in identification with different groups of gamers, as well as demographic variables of age and gender, exhibited distinct predictive patterns for individuals' motivations for playing boardgames. Collectively, these results provide initial evidence for the construct, convergent, predictive, and discriminant validity of the BGMS.

\section{Study 3: Boardgaming Motivations Scale Confirmation and Validation}

For maximum utility, the BGMS should reflect the motivations not only of the most dedicated boardgaming hobbyists, but also of more casual boardgamers who are not involved in online boardgaming communities. Study 3 was undertaken to confirm the structure of BGMS with less involved boardgamers and to further validate it.

\section{Method}

Following approval from the university’s Institutional Review Board, participants were recruited via Facebook ads to complete an online survey about motivations for playing boardgames. To reach more diverse individuals less involved in boardgaming, ads targeted individuals worldwide with interests related to boardgaming (see supplemental materials section 3 for the complete list), excluding those with an interest in BoardGameGeek. The questionnaire contained closed-ended questions about motivations for playing boardgames, preferences for boardgame genres, and motivations for playing videogames, as well as demographic variables. After completing the questionnaire, participants were able to opt into a drawing for one $\$ 50$ gift card.

\section{Participants}


After excluding six participants who did not respond to any items of the Boardgaming Motivations Scale and 10 who indicated they participated in Study 2, participants $(N=652)$ were on average 28.32 years old $(S D=10.15)$. Of those who reported gender $(n=642)$, most identified as male $(n=402,62.62 \%)$, followed by female $(n=229,35.67 \%)$ and nonbinary $(n=$ $11,1.71 \%)$. Of those who reported race $(n=599)$, most identified as White $(n=490,81.80 \%)$, followed by Asian $(n=52,8.68 \%)$. Of those who reported education $(n=639)$, most held at least a four-year degree $(n=332,51.96 \%)$, followed by some college $(n=131,20.51 \%)$ and high school $(n=108,16.90 \%)$. Of those who reported country of residence $(n=639)$, a plurality lived in Europe outside of the UK $(n=275,43.04 \%)$, followed by the United States $(n=166$, $25.98 \%)$. Participants had played boardgames for on average 11.81 years $(S D=10.12)$, and most $(n=374,57.36 \%)$ had visited one of the online discussion forums on which participants were recruited in Studies 1 and 2 in the six months prior to completing the Study 3 questionnaire. In comparison to Studies 1 and 2, participants had been playing boardgames for about the same amount of time, but were younger and demographically more diverse.

\section{Measures}

Boardgaming Motivations Scale. The 28-item BGMS from Study 2 was presented in random order, and participants were asked to rate their agreement (from $1=$ strongly disagree to $7=$ strongly agree $)$. Descriptive and psychometric statistics are presented in the Boardgaming Motivations Scale Confirmatory Analyses below.

\section{Validation Measures}

Videogaming motivations. Participants were asked if they played videogames, and for those who did ( $n=546,83.74 \%)$, motivations for playing videogames were measured using a 20-item measure of six videogaming uses and gratifications (VGUG; Sherry et al., 2006): 
competition, challenge, social interaction, diversion, fantasy, and arousal. One arousal item, "I play video games because they stimulate my emotions," was dropped for having large correlation residuals with three of four fantasy items (see supplemental material Section 2.2 for CFA details).

Demographics. Participants were asked to report their age, education level, gender, race/ethnicity, and current country of residence. Except for education level, which included eight options, all questions were open-ended and coded by the first author.

\section{Data Screening}

Prior to analysis, data were examined for evidence of participant speeding using the same procedure as in Study 2. For most pages of measures, six-to-nine participants' responses were nulled for speeding. For videogaming motivations, 13 participants' responses were nulled.

\section{Boardgaming Motivations Scale Confirmatory Analysis: Less Involved Boardgamers}

To confirm BGMS among individuals most different than participants in Study 2, analyses began with the subsample of participants $(n=278,42.64 \%)$ had not visited any of the online discussion forums through which participants were recruited in Studies 1 and 2 in the six months prior to completing the Study 3 questionnaire. Covariance coverage exceeded 98.9\% for all pairs of items. Confirmatory factor analysis (CFA) using MLR estimation indicated that the model failed the test of exact fit, and other fit indices suggested mediocre global fit, $\chi^{2}(329, n=$ $278)=614.701, p<.0001, \mathrm{RMSEA}=.056(90 \% \mathrm{CI}: .049, .063), \mathrm{CFI}=.888, \mathrm{SRMR}=.076$

Closer inspection revealed problems with the Player Interaction factor: two items had standardized loadings of only .508 and .436 , as well as large and significant correlation residuals with 21 and 16 of the other 25 items, respectively. After removing this factor, the six-factor model had improved fit, still failing the test of exact fit but with marginally acceptable global fit, 
$\chi^{2}(260, n=278)=466.449, p<.0001, \mathrm{RMSEA}=.053(90 \% \mathrm{CI}: .046, .061), \mathrm{CFI}=.912, \mathrm{SRMR}$ $=.063$.

Because an ESEM fit significantly better than a CFA model in Study 2, it is not surprising that a CFA model without cross-loadings had only marginally acceptable global fit. However, only one item had residual correlations consistent with cross-loading: the lusory item, "I boardgame for the activity of playing, not the outcome," had large correlation residuals with five of six group sociality items. Of the 24 other large, significant correlation residuals, only three exceeded .2 and none made clear conceptual sense for allowing indicator residuals to covary. Thus, only this item was allowed to cross-load on the group sociality factor - no other model modifications were implemented. For the model with one cross-loading, although the test of exact fit was still failed, other global fit indices suggested marginally acceptable global fit, $\chi^{2}(259, n=278)=451.328, p<.0001, \mathrm{RMSEA}=.052(90 \% \mathrm{CI}: .044, .060), \mathrm{CFI}=.918, \mathrm{SRMR}$ $=.058$. In comparison to the CFA model with one cross-loading, the model without this crossloading had significantly worse global fit, Satorra-Bentler scaled $\chi^{2}(1)=13.75, p<.001$. Additionally, of the revised model's 21 large and significant correlation residuals, only three exceeded .2. See Table 7 for standardized item coefficients and descriptives of manifest variable composites.

\section{Boardgaming Motivations Scale Confirmatory Analysis: More Involved Boardgamers}

Following the CFA with less involved boardgamers, a CFA was estimated with the subsample of participants $(n=374,57.36 \%)$ who had visited one of the online discussion forums through which participants were recruited in Studies 1 and 2 in the six months prior to completing the Study 3 questionnaire. Covariance coverage exceeded $99.7 \%$ for all pairs of items. CFA using MLR estimation indicated that the model failed the test of exact fit, but other 
fit indices suggested close global fit, $\chi^{2}(259, n=374)=457.557, p<.0001, \operatorname{RMSEA}=.045$

$(90 \% \mathrm{CI}: .038, .052), \mathrm{CFI}=.928, \mathrm{SRMR}=.051$. Of the 16 large correlation residuals, only one

exceeded .2. Additionally, the magnitude of the one specified secondary loading was small. The

six-factor, 25-item structure of BGMS was therefore confirmed. See Table 7 for standardized

item coefficients and descriptives of manifest variable composites.

Table 7

Boardgaming Motivations Scale Confirmatory Factor Analysis Results

\begin{tabular}{|c|c|c|c|}
\hline Factor & Item text & Std & eff. \\
\hline & & Invo & ment \\
\hline & $\underline{\text { Primary loadings }}$ & Less & More \\
\hline 1. Lusory & When I play boardgames, I don't care if I win. & .875 & .904 \\
\hline$M=4.69 / 4.90$ & Winning isn't important when I play boardgames. & .871 & .876 \\
\hline$S D=1.34 / 1.41$ & I boardgame for the activity of playing, not the outcome. & .374 & .598 \\
\hline$\alpha=\quad .76 / .83$ & & & \\
\hline 2. Immersion & I play boardgames for an interactive storytelling experience. & .760 & .792 \\
\hline$M=4.50 / 5.08$ & I play boardgames for the stories that emerge through gameplay. & .801 & .791 \\
\hline$S D=1.46 / 1.17$ & I play boardgames to get immersed in their worlds. & .806 & .744 \\
\hline$\alpha=\quad .86 / .83$ & Boardgames let me lose myself in a different world. & .761 & .624 \\
\hline 3. Group & I play boardgames because they involve gathering around a table with & & \\
\hline sociality & others. & .716 & .727 \\
\hline$M=5.50 / 5.70$ & I play boardgames because they engage a whole group. & .771 & .751 \\
\hline$S D=0.99 / 0.96$ & I play boardgames to socialize with others around the game. & .758 & .778 \\
\hline$\alpha=.84 / .84$ & I play boardgames to be face-to-face with others. & .646 & .644 \\
\hline & Boardgaming provides shared group experiences. & .562 & 621 \\
\hline & I play boardgames because they are a common focus for social interaction. & .671 & .636 \\
\hline 4. Community & I play boardgames to make friends I never would have met otherwise. & .744 & .858 \\
\hline$M=4.05 / 4.47$ & Boardgaming provides me new ways to make new friends. & .760 & .770 \\
\hline$S D=1.35 / 1.27$ & I play boardgames to meet like-minded people. & .709 & .646 \\
\hline$\alpha=.81 / .82$ & I play to engage with the boardgame community. & .667 & 669 \\
\hline 5. Mastery & I play boardgames for the personal challenge of figuring out a game. & .776 & .780 \\
\hline$M=5.26 / 5.46$ & I boardgame for the opportunity to figure out how to master a game. & .793 & .739 \\
\hline$S D=1.09 / 0.96$ & I play boardgames to solve challenging puzzles. & .593 & .549 \\
\hline$\alpha=\quad .75 / .75$ & It's gratifying to think of ways to play a boardgame more effectively. & $.440^{*}$ & .538 \\
\hline 6. Escapism & I play boardgames to relieve stress. & .833 & .556 \\
\hline$M=5.48 / 5.77$ & Boardgames let me escape everyday pressures. & .736 & .790 \\
\hline$S D=1.01 / 0.86$ & Playing boardgames provides a break from daily life. & .547 & .660 \\
\hline$\alpha=\quad .79 / .71$ & $\begin{array}{l}\text { Playing boardgames helps me relax. } \\
\qquad \underline{\text { Secondary loading }}\end{array}$ & .670 & .468 \\
\hline 3. Grp. Soc. & I boardgame for the activity of playing, not the outcome. & .252 & $.057 * *$ \\
\hline
\end{tabular}

Note. All standardized coefficients are $p<.001$ except where indicated by asterisks. Descriptives for less involved boardgamers are displayed to the left of the slash, those for more involved boardgamers to the right.

$* p=.01, * * p=.002$

\section{Boardgaming Motivations Scale Validation Analyses}


Because validation analyses required models with more parameter estimates than BGMS or VGUG measurement models in isolation, and because of the substantial similarity of factor loadings between less and more involved boardgamers in Study 3, all validation analyses were performed with the full Study 3 sample.

To assess the degree to which BGMS dimensions were related to VGUG dimensions, the final measurement models for both measures were allowed to freely correlate in a CFA using MLR estimation. The following relationships were anticipated between (dis)similar pairs of BGMS and VGUG dimensions: lusory and competition (inversely related), immersion and fantasy, group sociality and social interaction, community and social interaction, mastery and challenge, and escapism and diversion. Although the structural model was just-identified, despite failing the test of exact fit, other fit indices suggested acceptable global fit, $\chi^{2}(835, n=546)=$ 1519.620, $p<.0001, \mathrm{RMSEA}=.035(90 \% \mathrm{CI}: .033, .038), \mathrm{CFI}=.927, \mathrm{SRMR}=.045$. Although this model had 37 large correlation residuals, of which 21 were between BGMS and VGUG items, none were consistent enough to suggest cross-loading any items or collapsing any factors. The two correlation residuals that exceeded .2 were not between BGMS and VGUG. Thus, this model was retained and its factor correlations examined (Table 8). As expected, lusory and competition were significantly negatively correlated, while immersion and fantasy, group sociality and social interaction, community and social interaction, and mastery and challenge were significantly positively correlated. Contrary to expectations, escapism and diversion were not significantly correlated. Because BGMS escapism items referred to stress relief and relaxation, while VGUG diversion items referred to playing games despite other responsibilities, in retrospect this lack of significant correlation is not surprising. Overall, partial factor correlations were larger within both BGMS $(M=.28, S D=.17)$ and VGUG $(M=.42, S D=.17)$, 
respectively, than between them $(M=.14, S D=.16)$, suggesting that motivations to play these different types of games are relatively distinct.

Table 8 Partial Correlations among Boardgaming Motivations and Videogaming Uses and Gratifications

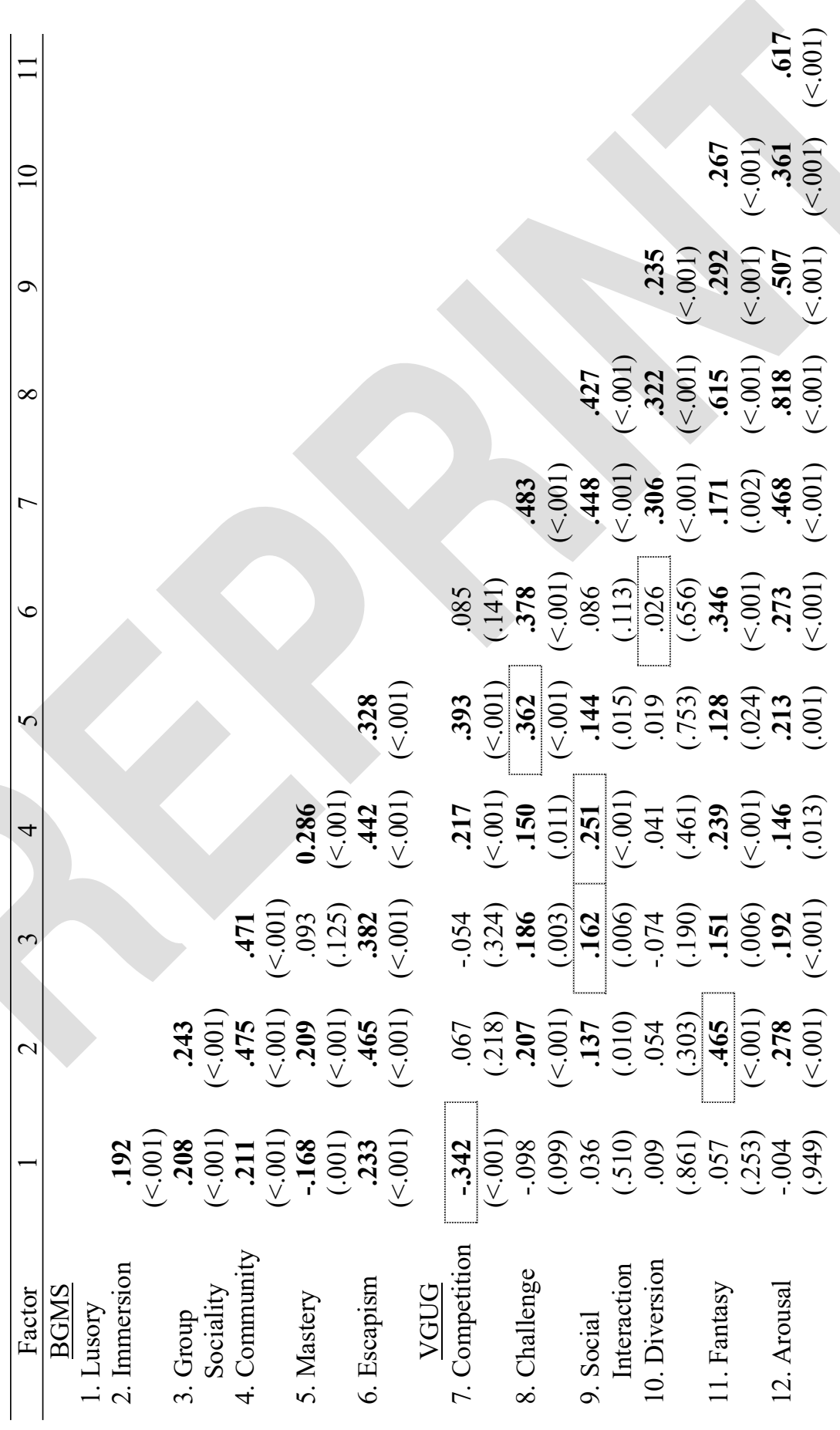


Note. $p$-values are in parentheses. Bolded correlations are $p<.05$. Anticipated partial correlations are surrounded by dotted boxes.

To assess the degree to which BGMS dimensions predicted preferences for boardgame genres, the three boardgame genre preference items were regressed on all BGMS dimensions using MLR estimation (Table 9). Although the structural model was just-identified, other fit indices suggested close global fit, $\chi^{2}(316, n=652)=702.755, p<.0001$, RMSEA $=.043(90 \%$ $\mathrm{CI}: .039, .048), \mathrm{CFI}=.928, \mathrm{SRMR}=.045$. For classic games, no BGMS factor was a significant unique predictor, potentially suggesting that classic games (e.g., Monopoly, Clue, Parcheesi) may be enjoyed for reasons other than those included in the BGMS, such as habit or tradition. Preferences for deduction and dexterity games were each predicted by distinct configurations of boardgaming motivations, again supporting BGMS's overall predictive validity and discriminant validity of its individual dimensions.

Table 9 Boardgame Genre Preferences Regressed on BGMS

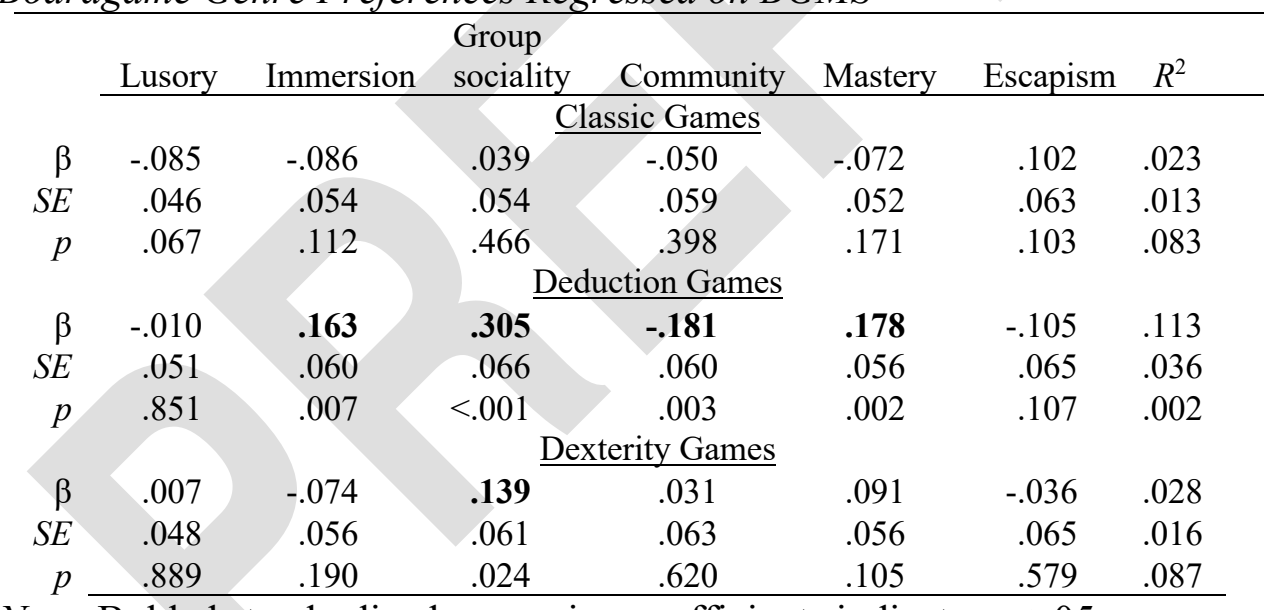

Note. Bolded standardized regression coefficients indicate $p<.05$.

\section{Brief Discussion}

Across both the less involved and more involved boardgamer subsamples in Study 3, after omitting the player interaction dimension, the factor structure of the BGMS identified in Study 2 was largely confirmed. Notably, the one secondary loading identified in the CFA among 
less involved boardgamers was smaller in the CFA among more involved boardgamers. In combination with the fact that factor intercorrelations were higher overall among less involved boardgamers, this fact may suggest that while the dimensions of boardgaming motivations identified here are relevant to all boardgamers, they are more conceptually distinct for more involved boardgamers. Boardgaming and videogaming motivations that were conceptually similar were positively correlated and dissimilar motivations negatively correlated. BGMS dimensions again exhibited distinct predictive patterns for participants' preferences for additional boardgame genres. Collectively, these results provide confirmatory evidence for the construct, convergent, predictive, and discriminant validity of the six-factor, 25-item BGMS.

\section{General Discussion}

The Boardgaming Motivations Scale (BGMS) appears to reflect a combination of motivations unique to boardgames, more general motivations shared by other media, and potentially medium-specific instantiations of motivations shared by other media. Specifically, community appears to be a novel gratification identified in this study. Although community is a social motivation, when past research has identified social gratifications, they have been interpersonal social interaction rather than feelings of belonging in a community of like-minded others (cf. Rubin, 1983; Sherry et al., 2006). Although the lusory dimension of BGMS, which is related to playing for playing's sake irrespective of game outcomes, appears to be the conceptual inverse of competition motivations (see Sherry et al., 2006), no items referring to competition from the initial BGMS item pool were retained. Moreover, the negative partial correlation between lusory boardgaming motivation and competition videogaming motivation was more modest than might be expected for a conceptual inverse. Thus, lusory motivation appears to be at least somewhat distinct from competition motivation. 
Many of the motivations found for playing boardgames in Studies 1 and 2 have been found in research on motivations for playing videogames. The immersion, group sociality, escapism, and mastery dimensions of BGMS parallel the fantasy, sociality, diversion, and challenge dimensions of videogaming motivations that have been most consistently found in videogaming research (e.g., Sherry et al., 2006). With the exception of escapism and diversion, which succumbed to a jingle fallacy, these parallels between boardgaming and videogaming motivations were empirically affirmed in Study 3.

Several medium-specific boardgaming motivations identified in Study 1 that would seem to be hallmark characteristics of boardgaming were not retained in in Study 2. Notably absent were medium characteristics like tangibility and lack of screens, which have been identified as important elements of enjoying boardgames in prior research (Rogerson et al., 2016; Woods, 2012). This departure from past findings may be related to our strict focus on motivations for play per se, as opposed to more general perceptions of enjoyment related to the boardgame hobby. Additionally, neither learning nor cognitive development dimensions were retained in BGMS, despite frequent appearance in Study 1 open-ended responses and the inclusion of information-seeking motivations for consuming other media such as television (Rubin, 1983). Their absence may suggest that learning and cognitive growth are more commonly perceived as a positive side-effect of boardgaming, rather than a motivation for playing them.

BGMS dimensions are closely connected to established communication and media phenomena. Immersion is a common media phenomenon (Arsenault, 2005), and immersion motivations appear to be related to experiencing narrative engagement (Busselle \& Bilandzic, 2008) and presence (Lombard \& Ditton, 1997). Associating immersion with boardgaming calls into question presumed superior immersiveness of high-fidelity digital graphics (cf. Ivory \& 
Kalyanaraman, 2007). Group sociality and community motivations play into interpersonal communication (Woods, 2012), relationship formation or maintenance (Rogerson \& Gibbs, 2018), and small-group communication (Xu et al., 2011) during boardgame play. Escapism motivations may suggest boardgames can dissipate noxious mood states to serve a mood management function similar to other media (Zillmann \& Bryant, 1985). Mastery motivations appear related to innate psychological needs for experiencing competence (Deci \& Ryan, 2000).

These studies are subject to limitations that present opportunities for future research. Demographically, both Study 1 and Study 2 were relatively homogenous: largely white, EuroAmerican, well-educated men, ages 25-45, and highly involved in boardgaming as a hobby. While these demographics are similar to those obtained in prior studies of boardgame hobbyists (Woods, 2012), Study 2 had an unusually high percent of female participants for this population, at over $20 \%$. Study 3 addressed some of these limitations by recruiting a less involved sample of participants, many of whom had never viewed the boardgaming forums from which participants in Studies 1 and 2 were recruited. In comparison to Studies 1 and 2, Study 3 participants were younger and demographically more diverse. Although overall larger correlations among BGMS dimensions in Study 3 than 2 may suggest that boardgaming motivations are less distinct for less involved boardgamers, the original structure of the BGMS from Study 2 was largely confirmed as stable after omitting the player interaction factor.

Future research should apply BGMS to predict and explain individuals' sociopsychological experiences and consequences of playing boardgames. In studies utilizing boardgames as naturalistic laboratories, participants' existing motivations likely influence their behavior in, experience during, and any outcomes of such research, including cognitive orientations during play (Martinez-Garza \& Clark, 2017) and social interactions with other 
players (Xu et al., 2011). In academic contexts using boardgames for game-based learning, different boardgaming motivations likely influence learning and transfer (Sherry, 2013), learning from opponents (Weintrop \& Wilensky, 2013), circulation of knowledge among students (Jiménez, 2015), and metacognitive responses to failure (Lee, Liu, Jullamon, \& Black, 2017). In recreational contexts, these motivations are expected to shape individuals' choices of boardgames to play. In turn, these differences likely produce different social, emotional, and cognitive consequences from gameplay, such as improved systems thinking ability (Kaufman \& Flanagan, 2016). 


\section{Acknowledgements}

The authors are grateful to Jaime Banks for assistance with Study 1 analyses and feedback on earlier versions of the manuscript; Elizabeth L. Cohen and Matthew M. Martin for feedback on earlier versions of the manuscript; Jay Spears and Stephanie Buggs for feedback on scale items; and Melissa J. Rogerson, Stewart Woods, Nicolas LaLone, Corey Butler, and Caleb T. Carr for helpful conversations and feedback at various times throughout this project. 


\section{References}

Ahn, S. J. (Grace), Johnsen, K., Robertson, T., Moore, J., Brown, S., Marable, A., \& Basu, A. (2015). Using virtual pets to promote physical activity in children: An application of the youth physical activity promotion model. Journal of Health Communication, 20, 807815. doi: $10.1080 / 10810730.2015 .1018597$

Arsenault, D. (2005). Dark waters: Spotlight on immersion. In GAMEON-NA International Conference Proceedings (pp. 50-52). Ghent, Belgium: Eurosis.

Asparouhov, T., \& Muthén, B. (2009). Exploratory structural equation modeling. Structural Equation Modeling: A Multidisciplinary Journal, 16, 397-438. doi:10.1080/10705510903008204

Barnett, M. A., Vitaglione, G. D., Harper, K. K. G., Quackenbush, S. W., Steadman, L. A., \& Valdez, B. S. (1997). Late adolescents' experiences with and attitudes toward videogames. Journal of Applied Social Psychology, 27, 1316-1334. doi:10.1111/j.15591816.1997.tb01808.x

Bowen, G. A. (2008). Naturalistic inquiry and the saturation concept: A research note. Qualitative Research, 8, 137-152. doi:10.1177/1468794107085301

Bowman, N. D., \& Tamborini, R. (2015). "In the mood to game": Selective exposure and mood management processes in computer game play. New Media \& Society, 17, 375-393. doi:10.1177/1461444813504274

Boyle, E. A., Hainey, T., Connolly, T. M., Gray, G., Earp, J., Ott, M., ... Pereira, J. (2016). An update to the systematic literature review of empirical evidence of the impacts and outcomes of computer games and serious games. Computers \& Education, 94, 178-192. doi:10.1016/j.compedu.2015.11.003 
Braun, V., \& Clarke, V. (2006). Using thematic analysis in psychology. Qualitative Research in Psychology, 3, 77-101. doi:10.1191/1478088706qp063oa

Busselle, R., \& Bilandzic, H. (2008). Fictionality and perceived realism in experiencing stories: A model of narrative comprehension and engagement. Communication Theory, 18, 255280. doi:10.1111/j.1468-2885.2008.00322.x

Cacioppo, J. T., \& Petty, R. E. (1982). The need for cognition. Journal of Personality and Social Psychology, 42, 116-131. doi:10.1037/0022-3514.42.1.116

Cleveland, A. A. (1907). The psychology of Chess and of learning to play it. The American Journal of Psychology, 18, 269-308. doi:10.2307/1412592

Deci, E. L., \& Ryan, R. M. (2000). The "what" and "why" of goal pursuits: Human needs and the self-determination of behavior. Psychological Inquiry, 11, 227-268. doi:10.1207/S15327965PLI1104_01

Dunbar, N. E., Miller, C. H., Lee, Y.-H., Jensen, M. L., Anderson, C., Adams, A. S., ... Wilson, S. N. (2018). Reliable deception cues training in an interactive video game. Computers in Human Behavior, 85, 74-85. doi:10.1016/j.chb.2018.03.027

Freedman, G., \& Flanagan, M. (2017). From dictators to avatars: Furthering social and personality psychology through game methods. Social and Personality Psychology Compass, 11, e12368. doi:10.1111/spc3.12368

Granic, I., Lobel, A., \& Engels, R. C. M. E. (2014). The benefits of playing video games. American Psychologist, 69, 66-78. doi:10.1037/a0034857

Gray, W. D. (2017). Game-XP: Action games as experimental paradigms for cognitive science. Topics in Cognitive Science, 9, 289-307. doi:10.1111/tops.12260

Griepp, M. (2018, July 30). Hobby games top \$1.5 billion in 2017. ICv2. Retrieved from 
https://icv2.com/articles/news/view/41016/hobby-games-top-1-5-billion

Hayton, J. C., Allen, D. G., \& Scarpello, V. (2004). Factor retention decisions in exploratory factor analysis: A tutorial on parallel analysis. Organizational Research Methods, 7, 191205. doi:10.1177/1094428104263675

Ip, J., \& Cooperstock, J. (2011). To virtualize or not? The importance of physical and virtual components in augmented reality board games. In J. C. Anacleto, S. Fels, N. Graham, B. Kapralos, M. S. El-Nasr, \& K. Stanley (Eds.), Entertainment computing - ICEC 2011 (pp. 452-455). Berlin, Germany: Springer Berlin Heidelberg. doi:10.1007/978-3-642-24500-8_64

Ivory, J. D., \& Kalyanaraman, S. (2007). The effects of technological advancement and violent content in video games on players' feelings of presence, involvement, physiological arousal, and aggression. Journal of Communication, 57, 532-555. doi:10.1111/j.1460-2466.2007.00356.x

Jansz, J., \& Tanis, M. (2007). Appeal of playing online first person shooter games. CyberPsychology \& Behavior, 10, 133-136. doi:10.1089/cpb.2006.9981

Jenkins, H. (2004). Game design as narrative architecture. In N. Wardrip-Fruin \& P. Harrigan (Eds.), First person: New media as story, performance, and game (pp. 118-130). Cambridge, MA: MIT Press.

Jiménez, O. (2015). Leveraging the social aspect of educational games. Theory Into Practice, 54, 101-108. doi:10.1080/00405841.2015.1010845

Juul, J. (2011). Half-real: Video games between real rules and fictional worlds. Cambridge, MA: MIT Press.

Kaufman, G., \& Flanagan, M. (2016). Playing the system: Comparing the efficacy and impact of 
digital and non-digital versions of a collaborative strategy game. In Proceedings of the First International Joint Conference of DiGRA and FDG.

Lee, A., Liu, C., Jullamon, M., \& Black, J. (2017). How'd that happen?! Failure in game spaces to prepare students for future learning. In K. E. H. Caldwell, S. Seyler, A. Ochsner, \& C. Steinkuehler (Eds.), GLS Conference Proceedings 2017 (pp. 119-128). Pittsburgh, PA: Carnegie Mellon ETC Press.

Lofgren, E. T., \& Fefferman, N. H. (2007). The untapped potential of virtual game worlds to shed light on real world epidemics. The Lancet Infectious Diseases, 7, 625-629. doi:10.1016/S1473-3099(07)70212-8

Lombard, M., \& Ditton, T. (1997). At the heart of it all: The concept of presence. Journal of Computer-Mediated Communication, 3. doi:10.1111/j.1083-6101.1997.tb00072.x

Marsh, H. W., Morin, A. J. S., Parker, P. D., \& Kaur, G. (2014). Exploratory structural equation modeling: An integration of the best features of exploratory and confirmatory factor analysis. Annual Review of Clinical Psychology, 10, 85-110. doi:10.1146/annurevclinpsy-032813-153700

Martinez-Garza, M. M., \& Clark, D. B. (2017). Two systems, two stances: A novel theoretical framework for model-based learning in digital games. In P. Wouters \& H. van Oostendorp (Eds.), Instructional techniques to facilitate learning and motivation of serious games (pp. 37-58). Cham, Switzerland: Springer. doi:10.1007/978-3-319-39298-1_3

McGloin, R., \& Embacher, K. (2018). "Just like riding a bike": A model matching approach to predicting the enjoyment of a cycling exergame experience. Media Psychology, 21, 486505. doi:10.1080/15213269.2017.1311269 
Nicholson, S., \& Begy, J. (2014). A framework for exploring tablet-based tabletop games. In Proceedings of the Canadian Game Studies Association Annual Conference: Borders without Boundaries.

Oliver, M. B., \& Raney, A. A. (2011). Entertainment as pleasurable and meaningful: Identifying hedonic and eudaimonic motivations for entertainment consumption. Journal of Communication, 61, 984-1004. doi:10.1111/j.1460-2466.2011.01585.x

Olson, C. K. (2010). Children's motivations for video game play in the context of normal development. Review of General Psychology, 14, 180-187. doi:10.1037/a0018984

Peng, W. (2009). Design and evaluation of a computer game to promote a healthy diet for young adults. Health Communication, 24, 115-127. doi:10.1080/10410230802676490

Peterson, J. (2012). Playing at the world: A history of simulating wars, people, and fantastic adventures: From chess to role-playing games. San Diego, CA: Unreason Press.

Reinecke, L., Tamborini, R., Grizzard, M., Lewis, R., Eden, A., \& Bowman, N. D. (2012). Characterizing mood management as need satisfaction: The effects of intrinsic needs on selective exposure and mood repair. Journal of Communication, 62, 437-453. doi:10.1111/j.1460-2466.2012.01649.x

Rogerson, M. J., \& Gibbs, M. (2018). Finding time for tabletop board game play and parenting. Games and Culture, 13, 280-300. doi:10.1177/1555412016656324

Rogerson, M. J., Gibbs, M., \& Smith, W. (2015). Digitising boardgames: Issues and tensions. In Proceedings of DiGRA 2015: Diversity of play: Games - Cultures - Identities.

Rogerson, M. J., Gibbs, M., \& Smith, W. (2016). "I love all the bits:” The materiality of boardgames. In Proceedings of the 2016 CHI Conference on Human Factors in Computing Systems (pp. 3956-3969). New York, NY: Association for Computing 
Machinery. doi:10.1145/2858036.2858433

Rosengren, K. E. (1974). Uses and gratifications: A paradigm outlined. In E. Katz \& J. G.

Blumler (Eds.), The uses of mass communications: Current perspectives on gratifications research (pp. 269-286). Beverly Hills, CA: Sage.

Rubin, A. M. (1983). Television uses and gratifications: The interactions of viewing patterns and motivations. Journal of Broadcasting, 27, 37-51. doi:10.1080/08838158309386471

Schubert, T. W., \& Otten, S. (2002). Overlap of self, ingroup, and outgroup: Pictorial measures of self-categorization. Self and Identity, 1, 353-376. doi:10.1080/152988602760328012

Selnow, G. W. (1984). Playing videogames: The electronic friend. Journal of Communication, 34, 148-156. doi:10.1111/j.1460-2466.1984.tb02166.x

Sherry, J. L. (2013). The challenge of audience reception: A developmental model for educational game engagement. New Directions for Child and Adolescent Development, 2013, 11-20. doi:10.1002/cad.20027

Sherry, J. L., Lucas, K., Greenberg, B. S., \& Lachlan, K. (2006). Video game uses and gratifications as predictors of use and game preference. In P. Vorderer \& J. Bryant (Eds.), Playing video games: Motives, responses, and consequences (pp. 213-224). New York, NY: Routledge.

Steinkuehler, C. A., \& Williams, D. (2006). Where everybody knows your (screen) name: Online games as "third places." Journal of Computer-Mediated Communication, 11, 885-909. doi:10.1111/j.1083-6101.2006.00300.x

Suits, B. (2014). The grasshopper: Games, life and utopia (3rd ed.). Toronto, ON: Broadview Press.

Swann Jr., W. B., Gómez, Á., Conor, D., Francisco, J., \& Huici, C. (2009). Identity fusion: The 
interplay of personal and social identities in extreme group behavior. Journal of Personality and Social Psychology, 96, 995-1011. doi:10.1037/a0013668

Vermeulen, L., Van Bauwel, S., \& Van Looy, J. (2017). Tracing female gamer identity. An empirical study into gender and stereotype threat perceptions. Computers in Human Behavior, 71, 90-98. doi:10.1016/j.chb.2017.01.054

Vinacke, W. E., \& Arkoff, A. (1957). An experimental study of coalitions in the triad. American Sociological Review, 22, 406-414. doi:10.2307/2089158

Weintrop, D., \& Wilensky, U. (2013). Know your enemy: Learning from in-game opponents. In Proceedings of the 12th International Conference on Interaction Design and Children (pp. 408-411). New York, NY: Association for Computing Machinery. doi:10.1145/2485760.2485789

Wood, D., Harms, P. D., Lowman, G. H., \& DeSimone, J. A. (2017). Response speed and response consistency as mutually validating indicators of data quality in online samples. Social Psychological and Personality Science, 8, 454-464. doi:10.1177/1948550617703168

Woods, S. (2012). Eurogames: The design, culture and play of modern European board games. Jefferson, NC: McFarland.

Xu, Y., Barba, E., Radu, I., Gandy, M., \& MacIntyre, B. (2011). Chores are fun: Understanding social play in board games for digital tabletop game design. In Proceedings of DiGRA 2011 Conference: Think Design Play.

Yee, N. (2006). The demographics, motivations, and derived experiences of users of massively multi-user online graphical environments. Presence: Teleoperators \& Virtual Environments, 15, 309-329. doi:10.1162/pres.15.3.309 
Yee, N. (2016, September 21). The board game motivation profile (v2): Based on data from over 40,000 gamers. Retrieved from http://quanticfoundry.com/2016/09/21/board-gameprofile-v2/

Yee, N. (2017, April 27). The primary motivations of board gamers: 7 takeaways. Retrieved from http:/quanticfoundry.com/2017/04/27/board-gaming-motivations/

Zillmann, D., \& Bryant, J. (1985). Affect, mood, and emotion as determinants of selective exposure. In D. Zillmann \& J. Bryant (Eds.), Selective exposure to communication (pp. 157-190). Hillsdale, NJ: NEA. 